\title{
Resposta a Hilan Bensusan \\ e Paulo A.G. de Sousa
}

\author{
Oswaldo Porchat Pereira*
}

\begin{abstract}
Resumo: Em resposta a críticas dirigidas contra a postura neopirrônica defendida pelo autor em artigo anterior (Porchat 3), mostra-se que elas provêm de uma incompreensão básica da noção de fenômeno no ceticismo grego.
\end{abstract}

Palavras-chave: pirronismo - neopirronismo - fenômeno

1. Muita coisa, por certo, não aparece ao neopirrônico. Muitas coisas, porém, lhe aparecem. Aparece-lhe, por exemplo, que uma leitura menos atenta de um texto pode, por vezes, ser causa de desnecessários mal-entendidos. É o que me parece ter acontecido com os autores do artigo Sobre o que Não Aparece (ao Neopirrônico) (Bensusan e Sousa 1, pp. 53-70) ${ }^{(1)}$. De qualquer maneira, sou-lhes agradecido por me propiciarem esta ocasião de retomar o tema cético do fenômeno.

Três são os pontos básicos da crítica desenvolvida naquele texto, visando a postura neopirrônica que expus em Sobre o que Aparece (Porchat 3) : entenderam que a noção de fenômeno carece de uma definição apropriada, que o neopirronismo abre flancos ao irracionalismo e que a ciência moderna é incompatível com essa postura. As três acusações parecem-me 
provir, todas elas, de uma compreensão inadequada da doutrina cética sobre o fenômeno, e creio que isso é fácil de mostrar. Para tanto, não terei de acrescentar nenhuma nova explicação ao que já se encontra naquele meu artigo, bastando-me relembrar algumas coisas que lá foram explicadas. Mas desde já devo dizer que a noção de fenômeno, tal como tematizada em Sobre o que Aparece, não é neopirrônica, mas simplesmente pirrônica. Em outras palavras, os mal-entendidos em que incorre a crítica a que estou replicando concernem imediatamente à própria doutrina de Sexto Empírico.

2. Essa incompreensão a respeito da doutrina sextiana do fenômeno é indissociável do modo defeituoso pelo qual nossos autores entenderam a suspensão cética do juízo (epokhé). Eles a viram como "constituída pela intersecção de duas faces" (Bensusan e Sousa 1, p. 54), a primeira sendo "a suspensão de juízo sobre o conjunto das proposiçães filosóficas e a consequiente impossibilidade de utilizá-la para orientar a prática cotidiana" (id., ibidem), a outra face dizendo "respeito indistintamente a qualquer tipo de proposição" (id., ibidem, p. 55) e mantendo, "acerca das proposições de senso comum, uma atitude proposicional que evita conotações dogmáticas" (id., ibidem) . Atribuiu-se, assim, ao neopirronismo a doutrina de que somente as proposições filosóficas são objeto da epokhé, subtraindo-se ao escopo desta as proposições de senso comum, que o neopirronismo aceitaria. Os autores propuseram-se a mostrar que o neopirronismo "não apresenta um critério para a delimitação do conjunto das proposições acerca do qual deve-se suspender o juízo", o que tornaria arbitrária a própria suspensão do juízo (id., ibidem, p. 58). Faltaria ao neopirronismo "um critério de demarcação entre o conjunto das proposições filosóficas, que interpretam o fenômeno, e o conjunto das proposições do senso comum, que descrevem o fenômeno" (id., ibidem), e a razão disso residiria em não ter o neopirronismo oferecido uma "distinção de natureza" entre descrição do fenômeno inteligível e interpretação do fenômeno.

3. Há aqui várias confusões a dissipar. Em primeiro lugar, a epokhé pirrônica é sempre particular, ela diz respeito a uma proposição ou doutrina dogmática específica sob consideração no momento, ela jamais diz respeito ao con- junto das proposições ou doutrinas de tal ou qual tipo. Cuidando por não incorrer, ele próprio, no dogmatismo que denuncia, o máximo que pode o cético dizer acerca das proposições dogmáticas é que até tal momento foi sempre levando à suspensão de juízo com relação àquelas sobre que se debruçou, devido à equipotência das razões que se podiam aduzir a seu favor e contra elas. Esse ponto da doutrina cética é bastante conhecido e tematizado pelos estudiosos, e Sexto nele insistiu várias vezes (por exemplo, em Sexto Empírico 4, H.P., I, pp. 199, 200, 203 etc.) .

Por outro lado, é incorreto atribuir ao pirronismo a doutrina de que "se deve" suspender o juízo sobre tal ou qual proposição. A epokhé é um estado em que o pirrônico se encontra após investigação das razões favoráveis e contrárias à aceitação de tal ou qual posição dogmática, ante a impossibilidade de uma opção justificada por alguma delas. Descobrimo-nos com o juízo suspenso, isto é, retido, a retenção do juízo não sendo ato que "devamos" praticar. Esse ponto foi amplamente elucidado em Sobre o que Aparece (Porchat 3, p. 86) .

4. Uma confusão mais importante concerne à relação entre filosofia e senso comum. Se é certo que os céticos gregos visaram de modo particular os discursos filosóficos da antiguidade e se aqueles filósofos que eles chamaram de dogmáticos foram seus alvos prediletos, eles não deixaram menos claro que sua epokhé, sempre particularizada sobre matéria submetida no momento à sua consideração, atingia "todo e qualquer discurso apofântico (no sentidb etimológico do termo), filosófico ou não fillosófico, sofisticado ou trivial, acompanhado ou desacompanhado de uma pretensa fundamentação, todo e qualquer discurso que nos queira 'fazer ver' a verdade. Ela atinge toda e qualquer crença humana que, formulada num juízo, se proponha como conhecimento verdadeiro de uma dimensão qualquer do mundo" (id., ibidem, p. 89; os itálicos são de agora). Esse meu texto é citado por extenso em NANP (Bensusan e Sousa 1, p. 55), mas fica-me a impressão de que nossos autores não quiseram demorar-se em melhor considerá-lo e em dele extrair as necessárias consequiências. Porque o que nessa passagem fica claro - e o ponto é retomado em outras passagens de Sobre o que Aparece e em outros artigos meus - é que a epokhé pirrônica se exerce sobre qualquer 
discurso tético investigado pelo cético, qualquer discurso que exiba a pretensão de dizer as coisas "como elas realmente são". Se essa dimensão dogmática - não consiste em outra coisa o dogmatismo, tal como o entendem os pirrônicos - é particulammente manifesta e confessada nos discursos filosóficos, o discurso não-filosófico também a exibe com alguma frequiência e não the é certamente imune o discurso do senso comum, cujo dogmatismo apenas carece da sofisticação própria ao discurso filosófico (Porchat 3, pp. 88-89; cf. também Porchat 2, p. 219) .

Que o senso comum é freqüentemente dogmático, que ele também está bastante impregnado por doutrinas religiosas, científicas e filosóficas, é algo evidente aos olhos de qualquer um, o pirrônico é o primeiro a reconhecê-lo. E não tem o pirrônico por que preocupar-se em estabelecer linhas de demarcação entre senso comum e filosofia. Nem tem tal demarcação, se acaso possível, algo a ver com a caracterização da suspensão cética do juízo. o que entra em pauta na problemática da epokhé é tão-somente o caráter tético ou não-tético do discurso, não a sua origem, se filosófica ou não filosófica. A confusão em que os autores de NANP incorreram a propósito dessa questão viciou definitivamente sua argumentação, ao longo de inúmeras páginas do artigo. Não parecem eles ter-se dado conta de que o que cai sob o escopo da suspensão cética do juízo é o discurso que se quer expressão da Verdade, veículo da apreensão do Real, instrumento do Conhecimento. Que se propõe a transcender nossa vivência imediata do mundo da experiência cotidiana. Esse é o discurso que se torna objeto da diaphonía das doutrinas, do conflito infindável e indecidível das interpretações.

5. A epokhé pirrônica não tem, portanto, duas faces de que seria a interseç̧ão, como se pretendeu. E isso sobretudo porque o fenômeno, o que aparece, é precisamente o que não cai sob o escopo da epokhé, por não concernir à controvérsia sobre discursos dogmáticos; o que resiste à suspensão do juízo porque sua aceitação não depende da opção por um certo juízo. O fenômeno se impõe a nós com necessidade e de modo imediato, numa experiência irrecusável que não podemos senão reconhecer. Um cético poderá eventualmente dizer que o reconhecimento desse nosso páthos é a outra face da epokhé, mas estará apenas significando o caráter, por assim dizer, resicual do fenômeno com relação às nossas suspensões de juízo, o fenômeno constituindo tudo aquilo que elas não podem atingir, o conteúdo mesmo de nossa experiência de vida, que se não deixa aprisionar em controvérsias doutrinárias.

6. Essa nossa experiência fenomênica, podemos dizê-la e a dizemos em nosso discurso cotidiano. Mas esse discurso que se limita a dizê-la, nãotético, está apenas a exprimir e descrever vivências imediatas, sensíveis ou inteligíveis. Em Sobre o que Aparece recorri didaticamente ao exemplo de um grupo de filísofos reunido em torno de uma mesa de bar (Porchat 3, pp. 95-97), a tomar chope e conversar não filosoficamente sobre amenidades, usando espontaneamente da linguagem cotidiana para falar sobre itens quaisquer de um experiência comum e como tal reconhecida, manifestando seu eventual acordo sobre alguns desses itens, concordando por exemplo em dizer "O chope está quente". Contrapus esse discurso àqueles que esses mesmos filósofos profeririam, entre si necessariamente conflitantes, se acaso levados a explicar e tematizar aquela experiência comum à luz de suas diferentes doutrinas. Pretendi ilustrar assim uma distinção conveniente a fazerse entre um uso descritivo próprio ao discurso fenomênico e um uso interpretativo próprio ao discurso dogmático, por exemplo ao discurso dogmático dos filósofos. O primeiro dizendo a fenomenicidade sensível ou inteligível, o segundo propondo-se a transcendê-la.

Situações como essa parecem-me autorizar claramente a distinção entre fenômeno e dogma, entre uso não-tético e uso tético da linguagem, entre descrição e interpretação. Didáticas e necessariamente relativas, tais distinções não se podem nunca pretender absolutas, não cabendo - e não cabendo sobretudo a um cético - querê-las fundadas "na natureza das coisas", o que quer que possa significar essa expressão. Nossos autores, no entanto, julgaram-se autorizados a exigir do cético que este apresente "uma distinção de natureza" entre descrição do fenômeno inteligível e interpretação do fenômeno. Não lhes ocorreu que propor distinçães de natureza e critérios formais num domínio como este é próprio apenas de quem dogmaticamente postula naturezas, formas ou essências; de quem julga ser nossa linguagem filosófica capaz de atingir a precisão das linguagens formais, de quem acre- 
dita que se podem impor à experiência humana do mundo categorizações moldadas sobre bases outras que não meramente "pragmáticas", de quem crê que a lógica de nosso discurso filosófico se pode construir sobre mais do que meras "contingências"... Quanto aos céticos, conduzidos por toda a sua postura a privilegiar a dimensão pragmática da linguagem, de há muito renunciaram eles a esses mitos.

7. Por outro lado, parece-me claro que não se pode reduzir a diferença apontada pelo pirronismo entre os discursos dogmático e fenomênico a uma diferença entre atitudes proposicionais, como se pretendeu. Segundo os autores de NANP, o neopirronismo faz corresponder ao discurso dogmático a atitude "acreditar que p", substituindb-a pela atitude "aceitar que p" (é assim que interpretam "aparece-me que p"), ao tematizar o discurso de fenômeno (Bensusan e Sousa 1, p. 55), alterando portanto a atitude proposicional (id., ibidem, p. 57). E entendem que o neopirronismo pretende substituir a crença nas doutrinas dogmáticas por "uma atitude mais fraca, de aceitação" (id., ibidam, p. 61) .

Alguns comentários se impõem. Em primeiro lugar, o neopirrônico suspende o juízo sobre se há, ou não, proposições, enquanto distintas de sentenças. Aliás, não se ignora que inúmeros e respeitáveis filósofos contemporâneos, que ninguém dirá céticos, julgam plenamente dispensável falar de proposições... Por outro lado, "crença" é um termo que se usa, como tantos outros da linguagem filosófica, em vários sentidos. Num sentido que podemos dizer mais "forte", "crença" (em grego: dógma) diz respeito à aceitação de uma pretensa verdade, à postulação implícita de uma correspondência entre nosso discurso e a chamada Realidade: tal compromisso ontológico toma então dogmática (no vocabulário cético) a crença correspondente. Mas "crença" se pode também usar num sentido mais fraco, significando simplesmente o reconhecimento do fenômeno, de uma experiência irrecusável que se impõe a nós. E, nesse sentido mais fraco, pode-se dizer que os céticos crêem, que eles crêem nos fenômenos, no aparecer que experienciam. Tal é a doutrina sextiana, como foi explicado em Sobre o que Aparece (Porchat 3, p. 104) .
Assim, quando o pirrônico diz "aparece-me que p", ele está significando que a sentença $\mathrm{p}$ lhe parece contar de modo razoavelmente adequado a experiência que está vivenciando, que se the impõe de modo necessário e irrecusável. E, nesse sentido, pode dizer-se também que ele "acredita que $\mathrm{p}^{\prime \prime}$. Se alguém prefere dizer que o cético está "aceitando que $\mathrm{p}$ ", este nada tem a opor-lhe, desde que esta frase não pretenda dizer mais que precisamente aquilo que o cético quer dizer com "aparece-me que p". No entanto, se a referência a uma "atitude proposicional", à atitude de "aceitar que p", tem outras implicações e pretende dizer algo mais, isso fica por conta e risco de quem assim se exprime, e o cético não terá, então, por que endossar tal uso linguístico.

8. Talvez seja oportuno considerar alguns exemplos introduzidos em NANP, nos quais se podem perceber melhor as dificuldades em que seus autores se enredaram. Assim, seja o caso de "o objeto que vejo persiste quando não observado" (Bensusan e Sousa 1, p. 59), que NANP toma como exemolo de um pressuposto filosófico do senso comum, cujo estatuto filosófico eu não teria reconhecido em Sobre o que Aparece. Ora, nesse artigo, comentando a noção pirrônica e sextiana de fenômeno inteligível, eu digo, a propósito de um objeto físico familiar, aparecer-me "que ele permanece e cura quando ninguém o está observando". Por que fenômeno inteligível? Porque se trata de algo que se impõe a meu entendimento, se filosoficamente desprevenido e desarmado, na experiência da vida coditiana; de algo que me vejo compelido a aceitar e de fato aceito, que não posso recusar e de fato não recuso, de algo em que creio (no sentido "fraco" de "crer") . E me é também fenômeno que assim aparece ao comum dos homens, que eles acreditam que assim se passam as coisas, isto é, que os objetos físicos familiares continuam a existir, independentemente de estarem sendo, ou não, observados.

Trata-se, então, de um "fenômeno comum" (Porchat 3, pp. 92-93) que, aliás, nos parece configurar uma crença humana imemorial, certamente anterior a toda e qualquer doutrina filosófica ou pronunciamento dogmático. Por isso mesmo, parece-me totalmente inadequado falar aqui de um pressu- 
posto filosófico do senso comum. Porque essa crença comum, os seres humanos de modo geral a temos, conheçamos ou não posições dogmáticas e reflexões doutrinárias acerca do estatuto ontológico ou epistemológico dos assim chamados objetos externos, sobre a relação entre objetos físicos e sense-data etc. Isto é, nós a temos, independentemente de nossa aceitação ou rejeição de qualquer doutrina. Para nossa vivência das crenças fenomênicas, os pronunciamentos dogmáticos sobre elas, quaisquer que eles sejam, são-nos, em geral, totalmente irrelevantes. Ninguém de bom senso filosófico suporá, por exemplo, que o imaterialismo de Berkeley ou o idealismo transcendental de Kant tenham privado esses filósofos de suas vivências e crenças fenomênicas, que eles deixaram de acreditar que suas mesas de trabalho permaneciam inteiras à sua espera quando delas se afastavam e ninguém mais as estava observando... É preciso cuidar por não confundir o registro fenomênico e não-filosófico da observância da vida com o registro filosófico, ou meramente dogmático, em que aquelas vivências e crenças se "interpretam".

Nada obsta, no entanto, a que a mesma expressão lingüística que exprime nossa experiência do fenômeno venha a receber, no registro filosófico ou dogmático, uma conotação que lhe confira uma dimensão ontológica ou epistemológica. "Há movimento aqui" pode dizer-se não-teticamente, relatando o fenômeno, assim como se pode também dizer filosófica ou dogmaticamente, exprimindo uma verdade (ou falsidade) filosófica, sob o prisma de tal ou qual doutrina. Sexto Empírico foi bastante claro e explícito a esse respeito. Assim, no que concerne ao movimento, ele expôs longamente, por um lado, os argumentos dogmáticos favoráveis ou contrários à realidade do movimento, cuja isosthéneia leva o cético à suspensão do juízo (Sexto Empírico 3, H.P. III, pp. 65-81; A.M. X, pp. 45-108). Mas, por outro lado, ele se referiu ao caráter incontestável dos relatos de nossas vivências cotidianas e banais de movimento (id., ibidem, H.P. III, p. 66) : afinal, mesmo quem nega a realidade do movimento reconhece, por exemplo, que sai de sua casa e que volta depois a ela... E Sexto lembrava de modo algo gaiato que "os que seguem a observância comum da vida empreendem viagens por terra e por mar, constroem navios e casas e fazem crianças, sem dar atenção aos discursos contra o movimento e a geração" (id., ibidam, H.P. II, p. 244) .
Sexto lembrava também o episódio da visita de Diodoro Cronos, autor de argumentos famosos contra a realidade do movimento, ao renomado médico Herófilo, para pedir-lhe que repusesse no lugar seu ombro deslocado: quando o médico invocou ironicamente seus argumentos para mostrar-lhe a impossibilidade de ter havido qualquer deslocamento, Diodoro lhe suplicou que deixasse, por um momento, os argumentos de lado e aplicasse a seu ombro as prescrições da arte médica (Sexto Empírico 3, p. 245) . Parecerme-ia que os autores de NANP acreditam que Diodoro não poderia, sem contradizer-se, fazer esse pedido a Herófilo...

Essa mesma dificuldade em distinguir o registro fenomênico do registro dogmático reaparece quando eles afi rmam (Bensusan e Sousa 1, p. 60) que o neopirronismo deveria suspender o juízo sobre a proposição 'corpos humanos são outras pessoas', pois deveria reconhecer seu caráter filosófico, não podendo ignorar as controvérsias filosóficas sobre, por exemplo, a existência de outras mentes. Entretanto, continuam eles, o neopirronismo não efetua nesse caso a epokhé, e não pode efetuá-la, sob pena de não mais poder criticar e argumentar contra posições dogmáticas, defendidas por outras pessoas. Uma vez mais, a confusão em que NANP incorre procede da não distinção entre o registro tético e o registro não-tético do discurso, da não compreensão de que uma mesma sentença ora simplesmente relata a experiência fenomênica, ora se usa carregada de conotações dogmáticas. E para o uso do discurso fenomênico pelo cético é totalmente irrelevante que tais ou quais itens de sua experiência fenomênica sejam objeto de problematizações filosóficas ou de controvérsias dogmáticas.

O cético se reconhece fenomenicamente inserido no mundo físico e humano e neles age e os diz em seu discurso (fenomênico), independentemente dos pronunciamentos filosóficos. Em Sobre o que Aparece fui bastante claro e explícito, parece-me, a esse respeito: ".. .me apareço como um vivente (zõon) humano, em meio aos outros seres humanos que coabitamos, todos, o mesmo mundo físico que nos envolve e de que compartilhamos a experiência, nele vivendo nossa vida comum. Este homem que sou me apareço como este corpo e estas sensações, emoções, paixões, sentimentos, representações, pensamentos que o acompanham. Meu eu sente e pensa, mas tem carne e osso também. Um corpo vivo como os outros corpos vivos 
do mundo, sentimentos e pensamentos como os dos outros homens. Vivendo numa contínua interação com eles, em meio às coisas e eventos do mundo" (Porchat 3, p. 102; os itálicos são de agora) . Quer parecer-me que nossos autores não atentaram suficientemente nessa passagem e em outras daquele artigo que comentam esse mesmo ponto. Eles parecem-me profundamente impregnados por aquele preconceito vulgar - curiosamente, no entanto, endossado por alguns círculos filosóficos - que se manifesta, por exemplo, na crença filosoficamente ingênua de que um filósofo dogmático que nega a existência de outras mentes, ou que dela duvida, se deveria proibir de tentar convencer alguém de seu ponto de vista...

9. A incompreensão acerca da noção pirrônica de fenômeno tem em NANP uma outra consequiência grave: os autores são levados a um total contrasenso sobre o significado e o alcance mais geral da postura pirrônica (ou neopirrônica), nela vendo "a configuração sub-reptícia de uma forma de irracionalismo" (Bensusan e Sousa 1, p. 63) , que teria como resultado "a paralisia da crítica, o retorno do dogmati.smo" (id., ibidem). Entendem eles que o neopirrônico, em consequiência de sua "restrição à irrecusabilidade e à relatividade do fenômeno", não tem como fazer a crítica efetiva das proposições dogmáticas de outrem nem como "revisar as proposições específicas que ele aceita" (id., ibidem, p. 62). Dogmatismo e irracionalismo surgiriam dessa "inexistência de critério para a revisão crítica do conteúdo de atitudes proposicionais" (id., ibidem, p. 62) . E, segundo eles, um neopirrônico não-fascista, na Alemanha nazista, não mais poderia fazer que "mudar sua atitude de crença para uma atitude de aceitação" (id. , ibidem) .

Revela-se aí uma surpreendente ignorância dos procedimentos argumentativos empregados pelos pirrônicos em sua incessante polêmica contra os dogmáticos. Não era esse o tema de Sobre o que Aparece, que não se propôs a analisar a prática cética que precede a epokhé(2). Mas uma leitura, mesmo superficial, da obra de Sexto Empírico torna imediatamente claro que a crítica cética ao discurso dogmático se exerce não pelo recurso aos fenômenos - o que seria, aliás, totalmente ineficaz -, porém mediante o uso "dialético" do próprio discurso dogmático. Como expliquei em Ceticismo e Argumentação (Porchat 2, p. 231), o cetici.smo faz o dogmatismo servir à denúncia do dogmatismo, ele usa o dogmatismo como instrumento. Opondo razões dogmáticas a razões dogmáticas, o cético pratica o "método das antinomias", "constrói" a equipotência (isosthéneia) dos discursos conflitantes e torna manifesta a impossibilidade de uma opção crítica por uma qualquer das posições dogmáticas consideradas. A suspensão do juízo não é mais que o desenlace inevitável de uma tal situação dialética. Os tropos de Enesidemo e os de Agripa servem precisamente para encaminhar o processo argumentativo nessa direção.

Porque o dogmatismo sempre pode renascer e efetivamente renasce, também porque o cético se proíbe coerentemente a universalização ou generalização dos resultados de sua pesquisa crítica, o ceticismo se assume como uma postura filosófica de investigação (zétesis) permanente, por isso mesmo se disse zetético. Ele privilegia decididamente, assim, o exercício crítico da razão e faz da desmistificação "dialética" do dogmatismo sua tarefa terapêutica permanente.

Por outro lado, a esfera fenomênica oferece toob um vasto e rico campo a ser explorado por uma razão liberta de entraves dogmáticos ou dogmatizantes. O pirronismo histórico não avançou muito nessa direção, ainda que nos tenha legado resultados importantes e propiciado indicações sugestivas, por exemplo, ao fazer a apologia da tékhne e dos procedimentos empíricos de investigação. Cabe ao neopirronismo aprofundar essa temática.

Nossos autores, como vimos, dizem também que o cético não tem como "revisar as proposições específicas que ele aceita". Um exemplo banal e simples é suficiente, no entanto, para mostrar como efetua o cético, se a ocasião para isso se apresenta, a "revisão" de suas crenças fenomênicas: ele a faz como a faz um homem qualquer. Suponhamos que apareça a alguém haver uma cobra num quarto mais ou menos escuro, sob uma cama, por exemplo. Que assim the apareçam as coisas, nesse momento e lugar, é algo que não pode negar nem questionar. Suponhamos agora que a mesma pessoa, momentos depois, armada de coragem e um pedaço de pau, mexa na suposta cobra e descubra que se trata apenas de uma corda enrolada. Aparece-lhe agora, é-lhe fenômeno, que descobriu tratar-se apenas de uma corda enrolada, aparece-l he agora que há pouco se enganara, pensando tratar-se de uma cobra. Era-lhe irrecusável que lhe aparecia então uma cobra, 
é-lhe irrecusável agora que não se trata de uma cobra, mas sim de uma corda. A sentença "É uma cobra" aparecia-lhe como descrição adequada da experiência então vivenciada, aparece-lhe agora que é inadequada, mas que é adequado e correto dizer-se "É uma corda enrolada". A correção do discurso operou-se de modo banal, como vezes inúmeras acontece aos seres humanos na experiência de cada dia.

A irrecusabilidade da experiência do fenômeno não é - de fato, não teria como ser - impedimento para a "revisão" das crenças fenomênicas, que tem lugar conforme os procedimentos costumeiros e pelas razões costumeiras. Julgar o contrário com frequiência provém da crença errônea de que não pode o cético, se coerente com sua postura, reconhecer enganos, ilusões perceptivas, erros etc. Talvez seja esse o caso de nossos autores. Se o for, devemos dizer em seu favor que se trata de um erro extremamente generalizado, produzido por uma má compreensão não menos generalizada do ceticismo pirrônico e pela longa familiaridade do pensamento filosófico com certas versões caricaturais do ceticismo moderno.

Tudo nos mostra, então, não apenas que o pirronismo é plenamente compatível com o exercício autocrítico da razão - seja na crítica dos devaneios dogmáticos seja no lidar com o domínio fenomênico -, mas que ele o é precisamente porque se define por esse exercício autocrítico com o qual, em última análise, se identifica. Mas, por isso mesmo, o pirronismo constitui o mais poderoso antídoto contra qualquer forma de irracionalismo.

10. Não quero ir adiante sem dizer uma palavra sobre os neopirrônicos nãofascistas que os autores de NANP imaginaram em plena Alemanha nazista (Bensusan e Sousa 1, pp. 62-63) , incapazes de uma postura crítica, nada mais podendo fazer do que "apelar para fenômenos comuns, isto é, apelar àquilo que aparece irrecusavelmente à maioria, sendo esta maioria definida historica e culturalmente", tendo, no máximo, a possibilidade de "mudar sua atitude de crença para uma atitude de aceitação" . Vimos acima quão descabida é a afimação de que está vedada ao cético uma postura crítica, consideremos agora sob este novo prisma a questão do fenômeno comum.

Se entendi bem o que os autores têm em mente, parece-me que estão a considerar, tomando como exemplo o caso da Alemanha nazista, situa- ções históricas em que uma determinada sociedade logrou de tal modo fazer aceitar uma doutrina dogmática pelo comum das pessoas, tendo-as "formado" e "echcado" através de mecanismos eficientes de condicionamento global, que as tornou incapazes de uma atitude crítica e as fez acreditar nos dogmas da doutrina como evidências irrecusáveis que "naturalmente" se impõem ao seu entendimento, sem a mínima consciência de todo esse processo. Então, aquilo que para um observador externo é manifestamente um dogma, é vivenciado por essas pessoas tão-somente como um fenômeno comum.

Como se comportaria um neopirrônico numa situação desse tipo? Se se trata de um neopirrônico, trata-se por definição de um filósofo cujo ceticismo se consolidou na crítica incessante aos pronunciamentos dogmáticos, na prática da argumentação antinômica, na incessante autocrítica. A postura não-fascista que, no caso da sociedade nazista, nossos autores lhe reconhecem, está, por certo, intimamente ligada a toda a sua postura filosófica. Ele não é membro da maioria condicionada e "ecucada" por uma eficiente lavagem cerebral (se dela tivesse sido membro, dificilmente teria tido condiçães para tornar-se não-fascista e filósofo cético; se o tivesse conseguido, teria sido por um processo de crítica e ruptura, de não aceitação e recusa do antigo condicionamento) . Ele pertence, então, à minoria que, por esta ou aquela razão, escapou ao processo coletivo de lavagem cerebral, minoria que não ignora o caráter dogmático do que aos membros da maioria se impõe como fenômeno comum e se pauta por outros valores, que não se conciliam com os dogmas da doutrina dominante. Essa minoria, que teve a felicidade de preservar o espírito crítico, não aceita nem pode aceitar o regime nazista; com mais fortes razões, não o aceita nem pode aceitá-lo o neopirrônico.

11. Finalmente, é dito em NANP que o neopirronismo "não pode compatibilizar-se com a ciência de hoje: ele não pode aceitá-la, nem sequer parcialmente, de um modo justificado" (Bensusan e Sousa 1, p. 64) . Lembrando o truísmo de que "a ciência constrói teorias que não guardam associação imediata com aquilo que observamos" (id., ibidem), nossos autores afirmam a seguir: "No entanto, diante das teorias científicas, Porchat, ao 
contrário do que faz com as teorias filosóficas, aceita-as como descrição das aparências" (Bensusan e Sousa 1, p. 64) . Tendo feito essa curiosa afirmação, fica-lhes então fácil inventar dificuldades para o neopirronismo: este teria de garantir um critério efetivo e aceitável de demarcação entre teorias científicas e filosóficas para legitimar aquela diferença de tratamento e, de outro lado, não tem como dar conta das diferenças entre filosofia e senso comum na própria descrição dos fenômenos (id., ibidem, pp. 6667) . Ou, então, o neopirronismo teria de estabelecer arbitrariamente, a propósito de cada teoria científica, uma distinção entre o que é passível de suspensão de juízo (porque discurso teórico) e o que se dirá descrição do fenômeno, sem no entanto dispor de critério efetivo para tal distinção.

Entretanto, o que eu disse em Sobre o que Aparece foi apenas que "o pirronismo parece-nos inteiramente compatível com a prática científica moderna e contemporânea" (Porchat 3, p. 113; o itálico é de agora, dou-me conta de que talvez devesse tê-lo usado já na redação original) . Mas a sequiência do texto parece-me deixar claro que o que eu tinha em mente era o progressivo privilégio conferido à investigação experimental na ciência moderna e contemporânea, o abandono do velho ideal da epistéme grega, o crescente distanciamento entre o desenvolvimento experimental da ciência e os pontos de vista metafísicos, ou mesmo epistemológicos. E acrescentei então (os itálicos são de agora) : "É muito fácil ver como toda essa postura, ao menos em seus aspectos mais fundamentais, é de índole essencialmente pirrônica. Ou pode, ao menos, tranqüillamente associar-se à concepção pirrônica da ciência. É como se tivéssemos assistido ao triunfo progressivo da velha tékhne sobre a veneranda epistéme. Por certo, a natureza bem mais complexa e rica da ciência moderna exige uma reelaboração e sofisticação das conceituações pirrônicas nesse campo, poderíamos mesmo dizer que tal seria uma das tarefas mais urgentes para um neopirrônico, hoje" (id., ibidem, p. 114).

Jamais poderia ter-me passado pela cabeça a tola idéia de que as teorias científicas modernas se reduzem, ou devem reduzir-se, a descrições de aparências. Ou que não estejam muitas vezes comprometidas com uma visão dogmática do mundo, por vezes associadas de modo estreito a doutrinas filosóficas. Ou que a imagem científica do mundo não colida freqüientemente com a imagem que dele oferece o senso comm. Nossos autores parecemme ter feito uma leitura algo precipitada da passagem acima reproduzida. Se nela se tivessem um pouco mais demorado, nela e nas páginas que imediatamente a precedem, ou nas que a seguem, ter-lhes-ia ficado manifesto que: 1) eu digo encontrar uma "índble" cética e pirrônica na ciência moderna, disso propondo alguns indícios; 2) eu sugiro como programa para uma investigação filosófica neopirrônica a elaboração de uma conceituação adequada que possa vir a dar conta dos traços fundamentais da ciência moderna, dentro do quadro conceitual do neopirronismo; 3) exceção feita para algumas rápidas observaçães adicionais, eu me limito a isso e não digo mais nada além disso.

Por isso mesmo, não me parece que deva aqui ocupar-me com resolver problemas eventualmente decorrentes de afirmações que não fiz e com as quais, aliás, não concordo. Já é tão difícil, às vezes, fazer compreender aquilo que, de fato, se disse...

São Paulo, janeiro de 1994

Abstract: In reply to criticisms proposed against the neo-pirmhonian stand taken by the author in a previous paper (Porchat 3), it is argued that they arise from a basic misunderstanding conceming the notion of phenomenon in ancient skepticism.

Key-words: pyrrhonism - neo-pyrrhonism - phenomenon 


\section{Notas}

(1) Usarei a sigla NANP para a ele referir-me.

(2) Essa prática foi por mim longamente analisada em Ceticismo e Argumentação.

\section{Bibliografia}

1. Bensusan, H. e Sousa, P.A.G. Sobre o que Não Aparece. In: discurso, n’ 23, São Paulo, 1994.

2. Porchat Pereira, O. Cetici.smo e Argumentação. In: Vida Comum e Ceticismo. São Paulo, Ed. Brasiliense, 1994

3. . Sobre o que Aparece. In: discurso, no 19, São Paulo, 1992.

4. Sexto Empírico. Sextus Empiricus, in four volumes. Cambridge (Massachusetts) e Londres, Loeb Classical Library, Harvard University Press and William Heinemann Ltd., vol. 1: Outlines of Pyrrhonism (H.P.) ; vols. 2-4: Adversus Mathematicos (A.M.) , 1976. 